\title{
Zinc supplementation prolongs the latency of hyperthermia-induced febrile seizures in rats
}

\author{
L Aydın ${ }^{1}$, SR Erdem ${ }^{2}$, C Yazıcı $^{3}$ \\ ${ }^{1}$ Department of Physiology, Faculty of Medicine, Baskent University, Ankara, Turkey \\ ${ }^{2}$ Department of Pharmacology, Faculty of Medicine, Baskent University, Ankara, Turkey \\ ${ }^{3}$ Department of Biostatistics, Faculty of Medicine, Baskent University, Ankara, Turkey
}

Received: August 18, 2015

Accepted: February 1, 2016

\begin{abstract}
Some studies have shown a relationship between febrile seizures and zinc levels. The lowest dose zinc supplementation in pentylenetetrazole seizure model has a protective effect. But, zinc pretreatment has no effect in maximal electroshock model. However, it is unclear how zinc supplementation affects hyperthermia-induced febrile seizures. The aim of the present study was to investigate the effects of zinc supplementation on febrile seizures in male Sprague-Dawley rats. The rats were randomly assigned to four groups. Zinc supplementation was commenced 5 days prior to febrile seizure induction by placing the animals in a water bath at $45^{\circ} \mathrm{C}$. We measured the rectal temperature and determined the febrile seizure latency, duration, and stage. In the zinc-supplemented group, both the seizure latency and the rectal temperature triggering seizure initiation were significantly higher than in the other groups. We suggest that zinc supplementation can positively modulate febrile seizure pathogenesis in rats.
\end{abstract}

Keywords: zinc supplement, febrile seizure, latency, body temperature, seizure threshold

Zinc $\left(\mathrm{Zn}^{2+}\right)$, one of the most common essential trace elements, is present in large amounts in the human body and plays roles in neurogenesis, neuronal migration, and synaptogenesis (20). The seizure-sensitive brain regions of the hippocampus and amygdala feature neuronal terminals containing large amounts of $\mathrm{Zn}^{2+}(4)$. The secretion of $\mathrm{Zn}^{2+}$ from presynaptic neuronal terminals into the synaptic cleft affects transmission by glutamatergic, gammaaminobutyric acid-ergic (GABAergic), and glycinergic synapses (13). Specifically, $\mathrm{Zn}^{2+}$ activates the enzyme "pyridoxal phosphate kinase" to produce pyridoxal phosphate, a cofactor in GABA synthesis. Thus, $\mathrm{Zn}^{2+}$ deficiency parallels low GABA levels in cerebrospinal fluid (CSF), triggering seizures (8). Studies of the pathogenesis of febrile seizures (FSs), the most common type of seizure in children, found that $\mathrm{Zn}^{2+}$ levels were low in both the serum and the CSF (16). The effect of $\mathrm{Zn}^{2+}$ treatment in different experimental seizure models have been evaluated by Kumar H. et al. (11). This study has shown that the lowest dose $\mathrm{Zn}^{2+}$ supplementation in pentylenetetrazole (PTZ) seizure model has a protective effect and the

Corresponding author: Dr. Leyla Aydın, MD, PhD

Başkent Üniversitesi Tıp Fakültesi Fizyoloji Anabilim Dalı

Eskişehir yolu 20. km, Bağlıca Kampusu, 06530 Bağlıca/Ankara/Türkiye

Phone: +90-312-2466666 /Fax: +90-312-2466689; 1540; E-mail: leyla3b@yahoo.com 
$\mathrm{Zn}^{2+}$ pretreatment in maximal electroshock (MES) model has no effect. However, it is unclear how $\mathrm{Zn}^{2+}$ supplementation affects FSs. The aim of the present study was to investigate the effects of $\mathrm{Zn}^{2+}$ supplementation on the hyperthermia (HT)-induced FSs.

\section{Materials and Methods}

\section{Ethical approval}

This study was approved by "Baskent University Ethics Committee for Animal Experiments" (Project DA13/01).

\section{Rats and $\mathrm{Zn}^{2+}$ administration}

A total of 32 male Sprague-Dawley rats (22-30 days old) were used. The rats were kept under normal laboratory conditions. The animals were fed pelletted food and had access to normal tap water ad libitum. The rats were assigned to one of four groups: group H, HT-induced group; group $\mathrm{ZH}, \mathrm{Zn}^{2+}$-supplemented and HT-induced group; group F, FS-induced group; and group $\mathrm{ZF}, \mathrm{Zn}^{2+}$-supplemented and FS-induced group.

All experiments were conducted between 09:00 and 12:00 h. $\mathrm{Zn}^{2+}$ supplementation $\left(\mathrm{ZnSO}_{4} \cdot 7 \mathrm{H}_{2} 0 ; 30 \mathrm{mg} / \mathrm{kg} /\right.$ day, via gavage) was commenced 5 days prior to FS or HT induction and continued throughout the study (2). Rats not undergoing $\mathrm{Zn}^{2+}$ supplementation received tap water via gavage.

\section{Rectal temperature measurements}

A "Medical Grade YSI 400" temperature probe, used for medical purposes, was employed.

\section{Induction of HT}

Groups in which FSs were not induced were held for $30 \mathrm{~s}$ in warm water $\left(45^{\circ} \mathrm{C}\right)$ to generate HT.

\section{FS induction}

FSs were induced by placing rats in a water bath at $45^{\circ} \mathrm{C}$, once a day for 4 consecutive days. The water level was maintained at neck level. The rats were kept in the water for a maximum of $4 \mathrm{~min}$. Rats that did not have seizures within this time were taken out of the water and evaluated as stage 0 . Rats that did have seizures were taken out of the water and placed on dry towels. Their body temperatures were measured as quickly as possible and they were observed until the seizures ended. Next, they were placed in a drying cage beside a heater and held there until dry (9).

Seizure latency was measured as the interval between the time the rat was placed in warm water and seizure onset. The first myoclonic spasm or sinking to the tank bottom after a short immobile period was defined as the onset of a seizure. Seizure duration was measured as the time from seizure onset to the end of the seizure. Regaining consciousness with correction of posture was defined as the end of a seizure (14).

Seizure severity was categorized into stages from 0 to 5 based on Racine's classification system (9). Seizure latency, seizure duration and stage were evaluated.

\section{Statistical analysis}

All data were analyzed using the software package SPSS (version 17; SPSS Inc., Chicago, IL, USA). Descriptive statistics were used, to describe discrete and continuous variables. 
Dunn's test was used for multiple comparisons. Independent group means of variables that failed to meet the assumptions of parametric tests were compared using the Kruskal-Wallis test and their dependent group means were compared employing Friedman's test. The level of statistical significance was set at $\alpha=0.05$.

\section{Results}

No mortality was observed during or after HT and FS induction, or indeed at any other time. All rats were weighed every day and all gained weight $(\mathrm{p}<0.001)$.

The group body temperatures did not differ significantly prior to HT or FS induction $(p=0.995)$. No significant difference in body temperature after HT induction was noted between groups $\mathrm{H}$ and $\mathrm{ZH}(\mathrm{p}=0.995)$. After FS induction, the body temperatures were 41.44 $\pm 0.23^{\circ} \mathrm{C}$ in group $\mathrm{F}$ and $42.65 \pm 0.46^{\circ} \mathrm{C}$ in group $\mathrm{ZF}$, and the difference was significant $(\mathrm{p}<$ 0.001 , Table I).

Table $I$. Body temperature changes $\left({ }^{\circ} \mathrm{C}\right)(\mathrm{n}=8)$

\begin{tabular}{|c|c|c|c|}
\hline Groups & Before procedure & After procedure & $\mathbf{p}$ \\
\hline $\mathrm{H}$ & $35.52 \pm 0.14$ & $39.01 \pm 0.18^{\mathrm{a}}$ & 0.001 \\
\hline $\mathrm{ZH}$ & $35.50 \pm 0.19$ & $39.04 \pm 0.16^{b}$ & 0.001 \\
\hline $\mathrm{F}$ & $35.42 \pm 0.18$ & $41.44 \pm 0.23^{\mathrm{a}, \mathrm{b}, \mathrm{c}}$ & 0.001 \\
\hline $\mathrm{ZF}$ & $35.35 \pm 0.35$ & $42.65 \pm 0.46^{\mathrm{a}, \mathrm{b}, \mathrm{c}}$ & 0.001 \\
\hline $\mathrm{p}$ & 0.995 & $\mathrm{a}, \mathrm{b}, \mathrm{c}=0.001$ & \\
\hline
\end{tabular}

H: Hiperthermia-induced group, $\mathrm{ZH}: \mathrm{Zn}^{2+}$ supplemented and hiperthermia-induced group,

F: Febrile seizure induced group, $\mathrm{ZF}: \mathrm{Zn}^{2+}$ supplemented and febrile seizure induced group

The FS latency was $145.47 \pm 10.88 \mathrm{~s}$ in group $\mathrm{F}$ and $172.97 \pm 23.50 \mathrm{~s}$ in group $\mathrm{ZF}$, and the difference was significant ( $\mathrm{p}<0.01$, Fig. 1). Thus, $\mathrm{Zn}^{2+}$ supplementation increased the seizure threshold and seizure latency significantly.

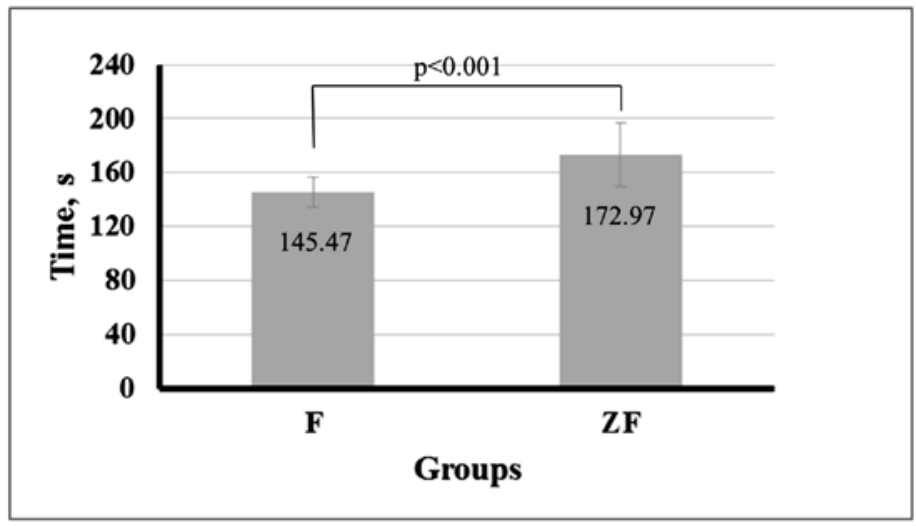

Fig. 1. FS latency values F: FS induced group $(\mathrm{n}=8), \mathrm{ZF}: \mathrm{Zn}$ supplemented and FS induced group $(\mathrm{n}=8)$ 
Two rats in the ZF group did not have any clinically evident seizures on the 3rd day (body temperatures 42.49 and $42.63{ }^{\circ} \mathrm{C}$ ), and one rat in the same group did not have any seizures on the 4 th day (body temperature $43.88^{\circ} \mathrm{C}$ ) of hyperthermia-induced FS.

The seizure durations in groups F and ZF were $64.25 \pm 23.40$ and $62.62 \pm 26.83 \mathrm{~s}$, respectively, but no significant difference was evident $(\mathrm{p}=0.959)$. The seizure stage in group $\mathrm{F}$ was $2.31 \pm 0.64$ while that in group ZF was $2.25 \pm 1.12$; no significant difference was evident $(\mathrm{p}=0.893)$. Thus, $\mathrm{Zn}^{2+}$ supplementation had no effect on seizure duration or stage.

\section{Discussion}

FSs are a common age-related type of seizure in children. Although simple FSs have a benign clinical course, focal and prolonged FSs may occasionally be associated with the later development of epilepsy and mesial temporal sclerosis (18). Much effort has been devoted to understanding FS pathogenesis, but little is known. HT causes seizures in many species by facilitating direct neuronal firing. Also, FSs tend to be associated with genetic mutations in sodium channel proteins, GABA-A receptors (15) and hyperpolarization-activated cyclic nucleotide-gated channel proteins (3). Additionally, HT-induced or interleukin-1 beta (IL-1 $\beta$ ) gene promoter mutation-related increases in IL-1 $\beta$ levels have been shown to play significant roles in FS induction. The increased seizure thresholds in rats with IL-1 $\beta$ receptor deficiencies supports the existence of such an IL-1 $\beta$-mediated effect (6), which is believed to influence (particularly) long-term neuronal excitability. Clinical studies have also suggested an association between FSs and $\mathrm{Zn}^{2+}$ levels. Mollah et al. (16) reported that children with FSs had lower serum and CSF $\mathrm{Zn}^{2+}$ levels compared to febrile children with no FSs. Seizuresensitive brain regions have high densities of zinc-containing neuronal terminals, and $\mathrm{Zn}^{2+}$ plays well-known roles in transmission at glutamatergic, GABAergic, and glycinergic synapses. These findings support the importance of $\mathrm{Zn}^{2+}$ in seizure pathogenesis (13).

Body temperature is a significant parameter in the pathogenesis of FS. However, only a few studies have investigated the correlation between body temperature and $\mathrm{Zn}^{2+}$. Konomi and Yokoi (10) investigated the effect of $\mathrm{Zn}^{2+}$ on body temperature, and concluded that an imbalance between $\mathrm{Zn}^{2+}$ and iron could affect body temperature set point. On the other hand, Partyka et al. (17) studied the anxiolytic-like activity of $\mathrm{Zn}^{2+}$, and found that $\mathrm{Zn}^{2+}$ decreased hyperthermia in a stress-induced hyperthermia test. However, this finding may be related to either the effect of $\mathrm{Zn}^{2+}$ on thermoregulatory mechanisms or its anxiolytic activity. As is evident from these studies, the effect of $\mathrm{Zn}^{2+}$ on body temperature is not clear. The present study was conducted to investigate the effect of $\mathrm{Zn}^{2+}$ supplementation on hyperthermiainduced FS. We induced hyperthermia in $\mathrm{H}$ and $\mathrm{ZH}$ groups to increase body temperature without causing FS, and did not find any significant difference in rectal temperature between the groups. Therefore, the higher rectal temperature in rats in the ZF group compared to those in the $\mathrm{F}$ group resulted from keeping them in hot water for a longer time rather than the effect of $\mathrm{Zn}^{2+}$ on thermoregulation.

Our work clearly shows that experimental $\mathrm{Zn}^{2+}$ supplementation prolonged the seizure latency and elevated the seizure threshold. Although, there is not enough research to examine $\mathrm{Zn}^{2+}$ supplementation in the seizures treatment, our findings are similar to the results of Kumar et al. (11). However, it is unclear whether $\mathrm{Zn}^{2+}$ supplementation modulates one or both of these parameters. $\mathrm{Zn}^{2+}$ deficiency renders GABA-mediated responses inadequate (21), and it is thus reasonable to suggest that $\mathrm{Zn}^{2+}$ might strengthen GABA-mediated 
inhibition. Additionally, $\mathrm{Zn}^{2+}$ increases postsynaptic neuronal inhibition by stimulating chlorine transport through metabotropic $\mathrm{Zn}^{2+}$-sensing receptor proteins (1). In the context of seizure threshold elevation, $\mathrm{Zn}^{2+}$-related, NMDA-receptor mediated effects likely play a role (19). However, as the rats used in the present study were not $\mathrm{Zn}^{2+}$-deficient prior to the study, we suggest that the effects of $\mathrm{Zn}^{2+}$ supplementation are independent of any prior $\mathrm{Zn}^{2+}$ deficiency. This idea should be explored in studies introducing $\mathrm{Zn}^{2+}$ supplementation after the induction of $\mathrm{Zn}^{2+}$ deficiency.

The onset of seizures is thought to result from an imbalance between excitatory and inhibitory mechanisms. Termination of the seizure determines its duration and severity, but the underlying mechanism is not well-understood. A number of mechanisms have been proposed to be responsible at the single-neuron level and local neuron networks for the termination of seizures, including intracellular ion-activated potassium currents, transmembrane ion gradients, membrane shunting, energy failure, glutamate depletion, increased GABAergic inhibition, the intra- and extracellular environments, gap junctions, and neuromodulators (12). In our study, $\mathrm{Zn}^{2+}$ decreased sensitivity to seizures but did not affect the duration or severity of the seizure, suggesting that $\mathrm{Zn}^{2+}$ affects seizure initiation rather than termination. Another factor that determines seizure duration and severity in FS is the duration of high body temperature (5).

In the experimental FS model used in the present study, rats were taken out of the water (thus, into room temperature) immediately after seizures commenced; their body temperatures dropped rapidly and HT was relieved. Therefore, to test for any direct effect of $\mathrm{Zn}^{2+}$ on seizure duration, it will be necessary to use an FS model featuring the activation of endogenous HT mechanisms (e.g., the lipopolysaccharide/kainic acid model).

In our study, we induced hyperthermia by FS in rats for 4 consecutive days, and found that three rats in the group administered $\mathrm{Zn}^{2+}$ did not have any seizures on the $3^{\text {rd }}$ and $4^{\text {th }}$ days of the study. This finding is in agreement with the results of Fallah et al. (7), who gave children with FS and normal $\mathrm{Zn}^{2+}$ levels $2 \mathrm{mg} / \mathrm{kg} /$ day of $\mathrm{Zn}^{2+}$, and observed a reduced recurrence of FS.

In conclusion, we found that $\mathrm{Zn}^{2+}$ supplementation in rats with no prior history of $\mathrm{Zn}^{2+}$ deficiency extended the seizure latency and elevated the seizure threshold by modulating the seizure mechanism.

\section{Acknowledgements}

We would like to thank Prof. Dr. Peter Camfield for editing. We also thank Aysenur Sahin, Umutcan Kuloglu, Bengisu Koc, Burcu Ozden, Seckin Sahin, and Zeynep Rzayeva, students of the Baskent University Faculty of Medicine, for their work as volunteers.

\section{Conflicting Interests}

No conflict of interest.

\section{Funding}

This study was funded by Baskent University Research Fund. 


\section{REFERENCES}

1. Chorin E, Vinog O, Fleidervish I, Gilad D, Herrmann S, Sekler I, Aizenman E: Upregulation of KCC2 activity by zinc-mediated neurotransmission via the mZnR/GPR39 receptor. J. Neurosci. 31, 12916-1226 (2011)

2. Cope EC, Morris DR, Scrimgeour AG, Levenson CW: Use of zinc as a treatment for traumatic brain injury in the rat: effects on cognitive and behavioral outcomes. Neurorehabil. Neural. Repair 26, 907-913 (2012)

3. Dibbens LM, Reid CA, Hodgson B, Thomas EA, Phillips AM, Gazina E, Cromer BA, Clarke AL, Baram TZ, Scheffer IE, Berkovic SF, Petrou S: Augmented currents of an HCN2 variant in patients with febrile seizure syndromes. Ann. Neurol. 67, 542-546 (2010)

4. Dube C, Chen K, Eghbal-Ahmadi M, Brunson K, Soltesz I, Baram TZ: Prolonged febrile seizures in the immature rat model enhance hippocampal excitability long term. Ann. Neurol. 47, 336-344 (2000)

5. Dubé C, McClelland S, Choy MK, Brewster AL, Noam Y, Baram TZ (2012): Fever, febrile seizures and epileptogenesis. In: Jasper's Basic Mechanisms of the Epilepsies, eds Noebels JL, Avoli M, Rogawski MA, Olsen RW, Delgado-Escueta AV, Fourth Edition. National Center for Biotechnology Information, Bethesda, USA, pp. 1-14

6. Dube C, Vezzani A, Behrens M, Bartfai T, Baram TZ: Interleukin-1 contributes to the generation of experimental febrile seizures. Ann. Neurol. 57, 152-155 (2005)

7. Fallah R, Sabbaghzadegan S, Karbasi SA, Binesh F: Efficacy of zinc sulfate supplement on febrile seizure recurrence prevention in children with normal serum zinc level: A randomised clinical trial. Nutrition 31, 1358 $1361(2015)$

8. Garty BZ, Olomucki R, Lerman-Sagie T, Nitzan M: Cerebrospinal fluid zinc concentrations in febrile convulsions. Arch. Dis. Child. 73, 338-341 (1995)

9. Jiang W, Duong TM, de Lanerolle NC: The neuropathology of hyperthermic seizures in the rat. Epilepsia 40, 5-19 (1999)

10. Konomi A, Yokoi K: Effects of zinc and/or iron deficiency on rectal temperature in rats. Biol. Trace Elem. Res. $109,49-54(2006)$

11. Kumar H, Jatinder K, Yogendra KG: Low dose zinc supplementation beneficially affects seizure development in experimental seizure models in rats. Biol. Trace Elem. Res. 163, 208-216 (2015)

12. Lado FA, Moshé SL: How do seizures stop? Epilepsia 49, 1651-1664 (2008)

13. Law W, Kelland EE, Sharp P, Toms NJ: Characterisation of zinc uptake into rat cultured cerebrocortical oligodendrocyte progenitor cells. Neurosci. Lett. 352, 113-116 (2003)

14. Łotowska JM, Łotowska MES, Sobaniec W: Ultrastructural features of astrocytes in the cortex of the hippocampal gyrus and in the neocortex of the temporal lobe in an experimental model of febrile seizures and with the use of topiramate. Folia Neuropathol. 47, 268-277 (2009)

15. Martin MS, Dutt K, Papale LA, Dubé CM, Dutton SB, de Haan G, Shankar A, Tufik S, Meisler MH, Baram TZ, Goldin AL, Escayg A: Altered function of the SCN1A voltage-gated sodium channel leads to gammaaminobutyric acid-ergic (GABAergic) interneuron abnormalities. J. Biol. Chem. 285, 9823-9834 (2010)

16. Mollah MAH, Rakshit SC, Anwar KZ, Arslan MI, Saha N, Ahmed S, Azad K, Hassan T: Zinc concentration in serum and cerebrospinal fluid simultaneously decrease in children with febrile seizure: Findings from a prospective study in Bangladesh. Acta Paediatrica 97, 1707-1711 (2008)

17. Partyka A, Jastrzębska-Więsek M, Szewczyk B, Stachowicz K, Sławińska A, Poleszak E, Doboszewska U, Pilc A, Nowak G: Anxiolytic-like activity of zinc in rodent tests. Pharmacol. Rep. 63, 1050-1055 (2011)

18. Patterson KP, Baram TZ, Shinnar S: Origins of temporal lobe epilepsy: Febrile seizures and febrile status epilepticus. Neurotherapeutics 11, 242-250 (2014)

19. Smart TG, Hosie AM, Miller PS: $\mathrm{Zn}^{2+}$ ions: Modulators of excitatory and inhibitory synaptic activity. Neuroscientist 10, 432-442 (2004)

20. Suh SW, Gum ET, Hamby AM, Chan PH, Swanson RA: Hypoglycemic neuronal death is triggered by glucose reperfusion and activation of neuronal NADPH oxidase. J. Clin. Invest. 117, 910-918 (2007)

21. Takeda A, Itoh H, Imano S, Oku N: Impairment of GABAergic neurotransmitter system in the amygdala of young rats after 4-week zinc deprivation. Neurochem. Int. 49, 746-750 (2006) 